Journal of Engineering and Applied Sciences 14 (Special Issue 5): 8949-8954, 2019

ISSN: $1816-949 \mathrm{X}$

(C) Medwell Journals, 2019

\title{
Vibration Transmission by Tractor to the Driver at Different Operation Sites
}

\author{
${ }^{1}$ A.A. Almosawi Abdulaziz and ${ }^{2}$ A.J Alkhafaji \\ ${ }^{1}$ Al-Furat Al-Awsat Technical University, Iraq \\ ${ }^{2}$ University of Kufa, Faculty of Agriculture, Iraq
}

\begin{abstract}
The aim of this study was to assess the WBV that the tractor driver exposed to while carrying out some traditional agricultural operations. The study involved three different investigations conducted at three different sites. Each investigation was considered as a single experiment and carried out individually at four different engine speeds $800,1000,1200,1600 \mathrm{rpm}$ except the plowing site, it was conducted at two speeds only $1200,1600 \mathrm{rpm}$. The experimental sites were the stop site for loading or unloading, the transportation site at asphalt road and earthen road with (2WD, 4WD) and plowing site with (2WD, 4WD). The effect of WBV at the orthogonal axes $(\mathrm{X}, \mathrm{Y}, \mathrm{Z})$, the total vibration of tractor seat $\mathrm{Av}$ and the time duration to reach exposure action value EAV and exposure limit value ELV were determined. The vibration was measured and defined in accordance with European Union regulation guide (2002/44/EC Directive) and the organization of ISO (ISO-2631-1-1997). The results indicated that irrespective of the type of operation, the rms acceleration levels along the longitudinal direction $\mathrm{Ax}$ axis was higher than the lateral direction $\mathrm{Ay}$ and the vertical direction $\mathrm{Az}$ at all speed tested. A strong correlation between the resultant of total vibration Av and Ax axis was found with $r$ equal to 0.97. The vibration values of $\mathrm{Ay}$ and $\mathrm{Az}$ axes were below the warning value $\mathrm{EAV}$ while the $\mathrm{Ax}$ and Av exceeded EAV and approached the risk value ELV in some engine speeds for both stop and transport sites. However, with respect to plowing site all orthogonal axes and Av exceeded the risk value ELV, Therefore, driving the tested tractor over a long period of time lead to a serious health problems and the driver must implement a serious measures. In general, from the health point of view and under the condition in which the research was conducted, the vibration of the tractor cannot be tolerated for more than $4 \mathrm{~h}$ at the lowest level of vibration of the stop site. While the shortest time of exposure to vibration was 23 min during the process of plowing.
\end{abstract}

Key words: Vibration, transportation, plowing, EAV, ELV

\section{INTRODUCTION}

A huge number of tractors in Iraq are engaged in agricultural work. Agriculture workers who drive these tractors are exposed to mechanical whole body vibration, which is considered to be harmful to an extent based on the factors and circumstances of the work such as engine rpm, speed of travel, road nature and field conditions.

Mechanical vibration is defined by Karthik et al. (2017) as mechanical wonder where by motions happened around a harmony point. Mechanical vibration is undesirable because it has direct effects on the vitality of the operator body and end with undesirable sound that effect his hearing system as well as discomfort, back pain and injury in high vibration situations (Mehta et al., 2000). Fereydooni et al. (2017) reveled that vibration enter human body in three directions these are $\mathrm{X}, \mathrm{Y}$ and $Z$. X direction enter from behind of head to front of heart, $\mathrm{Y}$ direction from right shoulder to left shoulder and $\mathrm{Z}$ from human foot to up hand. Therefore, the accelerometer should be placed in the entrance place. Agricultural machines such as tractor, harvester that operated by internal combustion engine and traveled on rough ground cause a drumming vibration leading driver to discomfort and sometimes in ranges considered hazardous to driver health. Kitazaki and Griffin (1997) found that vibration with frequencies below $10 \mathrm{HZ}$ results in harm full effect on several body organs such as deformations of the spin and buttocks furthermore pitching motion of pelvis and head. Vibration exposure values should not exceed the values allowed for driver retention based on the European and council directive 2002/44/EC (European Communities, 2002), the International organization for standardization ISO 2631-1:1997 (ISO, 1997) and the International organization for ISO 2631-5: 2004 (ISO., 2004). In this contexts Scarletl et al. (2007) studied the emission ranges of whole-body vibration (WBV) and exposure levels of number of agricultural tractors while performing some identical and traditional field operations. The WBV exposure levels limitation values were adopted according to the European physical agents vibration directive: 2002 (PA(V)D). The results showed that more than $90 \%$ of the tractor tested exceeded the exposure limit value (ELV) and exposure action value (EAV) during an $8 \mathrm{~h}$ working day or more.

Corresponding Author: A.A. Almosawi Abdulaziz, Al-Furat Al-Awsat Technical University, Iraq 
By the way, NFU Mutual Risk Management Service (2017) has defined EAV as the amount of daily exposure to whole body vibration above which you are required to take action to reduce risk. On the other hand, the ELV also has been defined by the same organization as the maximum amount of vibration an employee may be exposed to on any single day. However; Scarlett et al. (2005) opinion is that ELV level should not be seen as a safe level of vibration exposure during daily work hours but should be considered as a high, undesirable level of vibration exposure to be avoided.

Monaghan and Van Twest (2004) stated that vibration can be described by one of three methods, root mean square (RMS), acceleration vibration dose value (VDV) and equivalent static compressive stress, Se. Each of the mentioned methods provides descriptions of the measure or severity of the vibration, when the vibration peak required, it appears that the RMS is the most applicable parameter. However, VDV evaluation seems to be more applicable than RMS in characterizing the effects of vibrations on long-term health effect. A conservative analysis approach is to apply the worst case of the three method. Since the agricultural tractor engine forms the first source of vibration followed by the gearbox, tractor tires, terrain and type of agricultural operation. Therefore, the engine speed was selected as a main factor of this research with reference to the tractor speed. The aims of this research were to estimate the amount vibrations emitted by tractor during a daily routine work and during a selected field operation and their effect on the tractor driver.

\section{MATERIALS AND METHODS}

The research was carried out at the fields of the Faculty of Agriculture University of Kufa, Iraq to determine the levels of vibration exposure that are emitted by agriculture tractors. The investigations were performed during:

- Daily routine work such as driving on asphalt road, driving inside the field on earthen road (2WD and $4 \mathrm{WD}$ ) or stopping for loading or unloading when the engine is in operation

- A traditional agricultural operation that consume high power, in this regard the moldboard plow was selected for the plowing operation at $20 \mathrm{~cm}$ depth using (2WD and 4WD)
For the experimental tests a $82 \mathrm{hp} \mathrm{Massy} \mathrm{Fergusson}$ tractor was used at five engine operational speeds, these are $800,1000,1200,14001600 \mathrm{rpm}$. The experiment was design as RCBD with three replications. The main specifications of the tractor are presented in Table 1. It should be noted that the engine speed of $1400 \mathrm{rpm}$ was excluded from the search due to data storage failure.

Before vibration measurements were taken, locations were selected where the data were taken and the measurement issue was determined according to the experimental design. A $100 \mathrm{~m}$ testing track was identified on the asphalt road and the same distance for the earthen road and plowing. The testing tracks were randomly replicated three times for testing purposes. The tractor has been turned on a period of time to normalize the tractor operating conditions and the meters of the engine rpm, tractor speed and engine temperature were inspected for normal work. A portable ERBESSD Ei-Calic vibration measuring device was employed for data collection. The specifications of this device are shown in Fig. 1. This device was linked to Pc during measurement. The changeability in vibration depend on treatment nature and acquisition interval, therefore, the assessor required to be sitting next to the driver seat to take reading and saved it in the personal computer when vibration transmitted to the seated driver as WBV through the body buttock. The accelerometer was mounted to the metal base below the tractor driver seat and the acceleration was measured in three orthogonal axes ( $\mathrm{X}, \mathrm{Y}$ and $\mathrm{Z}$ ). In the $\mathrm{X}$-axis, vibration enter from the back of the driver body toward the front, in the $\mathrm{Y}$-axis vibration enter from the left side of the body to the right, while, in the Z-axis vibration enter from the feet up to the head. A set of vibration readings were taken to verify the work of the vibration

Table 1: The main specifications of the tractor

\begin{tabular}{lll}
\hline Parameters & Measurement unit & Values \\
\hline Maximum power & Kw (Hp) & $61(82)$ \\
Maximum torque at $2400 \mathrm{rpm}$ & $\mathrm{N} . \mathrm{m}$ & 394 \\
Engine type & & 4 stroke-perkins \\
Injection & & Direct injection \\
Capacity & $\mathrm{L}$ & 4.4 \\
No. of forward speeds & & 12 speeds \\
No. of rear speeds & & 4 speeds \\
Total weight & $\mathrm{kg}$ & 3040 \\
Dimensions & & \\
Maximum length & $\mathrm{M}$ & 3.89 \\
Minimum width & $\mathrm{M}$ & 2.6 \\
Height above exhaust & $\mathrm{M}$ & 2.53 \\
\hline
\end{tabular}

\begin{tabular}{lccccc|} 
Sensitivity & Weight & Dimension & Frequency range & Amplitude range & Connector \\
\hline $330 \mathrm{Mvg}^{-1}$ & 45 & $\begin{array}{l}0.625^{\prime \prime} \text { dim } \\
1.625^{\prime \prime} \text { long }\end{array}$ & $1 \mathrm{~Hz}-8 \mathrm{kHz}$ & $\begin{array}{l}6 \text { g peak } \\
\text { To peak }\end{array}$ & $5 \mathrm{pin}$
\end{tabular}

Fig. 1: ERBESSD Ei-Calic vibration measuring device and its specifications 
device before the field measurements. The root means square $\mathrm{rms}$ acceleration (ai) was calculated by using equation 1 along the three axes $(i=x, y, z)$. A correction factor Ki was used to meet the health aspects according to the international standards of the person sitting on seat at $\mathrm{Kx}$ and $\mathrm{Ky}$ value of 1.4 while $\mathrm{Kz}$ equals 1 . The vector sum of rms (Av) was calculated using equation 2. The daily vibration exposures value were determined on the basis of an $8 \mathrm{~h}$ at one work day which were calculated by using Eq. 3-5.

$$
a_{\mathrm{i}}=\left[1 / \mathrm{T} \int_{0}^{\mathrm{T}} \alpha^{2}(\mathrm{t}) \mathrm{dt}\right]^{1 / 2} \min \sec ^{-2}
$$

Where:

$a_{i}$ : Root means square rms acceleration $(i=x, y, z \ldots i)$

$\mathrm{a}:$ The acceleration acquired at seat $\min \mathrm{sec}^{-2}$

$$
\begin{gathered}
\mathrm{Av}=\left[(1,4 * \mathrm{ox})^{2}+\left(1.4^{*} \mathrm{ay}\right)^{2}+\left(1.0^{*} \mathrm{az}\right)^{2}\right]^{1 / 2} \mathrm{~min} \mathrm{sec}^{-2} \\
\mathrm{Ax}(8)=1.4 \mathrm{a} \sqrt{\left(\mathrm{T} / \mathrm{T}_{0}\right)} \operatorname{minsec}^{-2} \\
\mathrm{Ay}(8)=1.4 \mathrm{ay} \sqrt{\left(\mathrm{T} / \mathrm{T}_{0}\right)} \mathrm{minsec}^{-2} \\
\mathrm{Az}(8)=1.0 \mathrm{az} \sqrt{\left(\mathrm{T} / \mathrm{T}_{0}\right)} \min \sec ^{-2}
\end{gathered}
$$

Where:

$\mathrm{T}$ : Time of daily exposure to combine vibration in hour $\mathrm{T}_{0}$ : Time interval of daily $8 \mathrm{~h}$ work $(2002 / 44 / \mathrm{EC}$ Directive)

\section{RESULTS AND DISCUSSION}

The results of weighted rms acceleration levels in X, $\mathrm{Y}$ and $\mathrm{Z}$ directions at different engine rpm are illustrated in Table 2. Irrespective of the type of operation, the rms acceleration levels along the longitudinal direction $\mathrm{Ax}$ axis was higher than the lateral direction Ay and the vertical direction $\mathrm{Az}$ at all operations tested. This result is consistent with former studies where high vibration levels were reported at longitudinal direction Barac et al. (2018). The results also pointed out that the variations in the type of operation led to which of the axes has the most influential vibration.

For comparison purposes the relationship between the average vibration values of the three orthogonal axes $(\mathrm{X}, \mathrm{Y}, \mathrm{Z})$ and the recommended values by the European Physical Agents (vibration) Directive: 2002 (PA (V) D) EAV (exposure action value) and ELV (exposure limit value) at different engine rpm were graphed for each operation individually.

Stop site: Figure 2 describe the nature of vibration while the tractor in stop site and the engine was operated at different rpm. The figure also depicts comparison between the values obtained and the limits set by the 2002 (PA (V) D) to assess the effect of agricultural operation in terms of vibration. Accordingly decisions could be made regarding the time of the driver safety in conjunction with the agricultural process. From the observations of Fig. 2, the $Z$-axis is the least vibrating and its values showed a slight and a gradual increase as the engine rpm increase.

\begin{tabular}{|c|c|c|c|c|c|c|}
\hline Sites & Tractor operation & Engine rpm & $\begin{array}{l}\text { Longitudinal } \\
\left.\text { Ax (min } \sec ^{-2}\right)\end{array}$ & $\begin{array}{l}\text { Lateral Ay } \\
\left(\text { min } \sec ^{-2}\right)\end{array}$ & $\begin{array}{l}\text { Vertical Az } \\
\left.(\text { min sec })^{-2}\right) \\
\end{array}$ & $\begin{array}{c}\text { Total vibration of } \\
\text { seat } \mathrm{Av}\left(\mathrm{min} \mathrm{sec}^{-2}\right)\end{array}$ \\
\hline \multirow[t]{4}{*}{$\overline{\text { Stop }}$} & \multirow{4}{*}{ Engine only on operation } & 800 & 0.58 & 0.15 & 0.100 & 0.61 \\
\hline & & 1000 & 0.59 & 0.17 & 0.140 & 0.63 \\
\hline & & 1200 & 0.96 & 0.23 & 0.140 & 1.00 \\
\hline & & 1600 & 0.99 & 0.31 & 0.210 & 1.21 \\
\hline \multirow[t]{12}{*}{ Transportation } & \multirow[t]{4}{*}{ Driving on asphalt road } & 800 & 0.63 & 0.13 & 0.007 & 0.65 \\
\hline & & 1000 & 0.68 & 0.25 & 0.180 & 0.75 \\
\hline & & 1200 & 0.83 & 0.18 & 0.190 & 0.87 \\
\hline & & 1600 & 0.69 & 0.27 & 0.200 & 0.77 \\
\hline & \multirow[t]{4}{*}{ Driving on earthen road $2 W D$ mode } & 800 & 0.91 & 0.24 & 0.110 & 0.95 \\
\hline & & 1000 & 0.61 & 0.25 & 0.120 & 0.67 \\
\hline & & 1200 & 0.74 & 0.66 & 0.190 & 1.01 \\
\hline & & 1600 & 0.82 & 0.40 & 0.170 & 0.93 \\
\hline & \multirow{4}{*}{ Driving on earthen road $4 \mathrm{WD}$ mode } & 800 & 0.84 & 0.33 & 0.130 & 0.91 \\
\hline & & 1000 & 1.01 & 0.52 & 0.160 & 1.15 \\
\hline & & 1200 & 1.65 & 0.40 & 0.140 & 1.70 \\
\hline & & 1600 & 2.72 & 0.52 & 0.200 & 2.87 \\
\hline \multirow[t]{4}{*}{ Plowing } & \multirow[t]{2}{*}{$2 \mathrm{WD}$ engaged with mold board } & 1200 & 3.23 & 3.83 & 2.410 & 5.55 \\
\hline & & 1600 & 2.63 & 1.49 & 2.110 & 3.69 \\
\hline & \multirow[t]{2}{*}{ 4WD engaged with mold board } & 1200 & 3.57 & 2.46 & 3.610 & 5.64 \\
\hline & & 1600 & 2.76 & 1.27 & 1.240 & 3.28 \\
\hline
\end{tabular}
The Ay axis has the same behavior as the Az axis, both of which did not exceed the limits allowed by PA(V)D Exposure Action Value (EAV) while the Ax exceed the

Table 2: Weighted rms acceleration in $\mathrm{X}, \mathrm{Y}$ and $\mathrm{Z}$ axes at different engine rpm and different operation sites 
J. Eng. Applied Sci., 14 (Special Issue 5): 8949-8954, 2019

Table 3: The total vibration of tractor seat $A v$ and the daily vibration exposure $A(8)$

\begin{tabular}{|c|c|c|c|c|c|c|c|}
\hline \multirow[b]{2}{*}{ Sites } & \multirow[b]{2}{*}{ Tractor operation } & \multirow[b]{2}{*}{$\begin{array}{c}\text { Engine } \\
\text { RPM }\end{array}$} & \multirow[b]{2}{*}{$\begin{array}{l}\text { Total vibration of } \\
\text { seat } \mathrm{Av}\left(\operatorname{min~} \mathrm{sec}^{-2}\right)\end{array}$} & \multirow[b]{2}{*}{$\begin{array}{l}\text { Time to EAV } \\
(\mathrm{A}(8)) \mathrm{h}: \mathrm{min}\end{array}$} & \multirow[b]{2}{*}{$\begin{array}{l}\text { Time to ELV } \\
(\mathrm{A}(8)) \mathrm{h}: \mathrm{min}\end{array}$} & \multicolumn{2}{|c|}{ Exceeding value } \\
\hline & & & & & & $\mathrm{EAV}$ & ELV \\
\hline \multirow[t]{4}{*}{ Stop } & Engine only on operation & 800 & 0.61 & $0: 45$ & $3: 58$ & $\sqrt{ }$ & \\
\hline & & 1000 & 0.63 & $0: 42$ & $0: 44$ & $\checkmark$ & \\
\hline & & 1200 & $1: 00$ & $0: 16$ & $1: 25$ & $\checkmark$ & \\
\hline & & 1600 & 1.21 & $0: 15$ & $1: 21$ & $\checkmark$ & $\checkmark$ \\
\hline \multirow{12}{*}{ Transportation } & Driving on asphalt road & 800 & 0.65 & $0: 37$ & 3:20 & $\checkmark$ & \\
\hline & & 1000 & 0.75 & $0: 32$ & $2: 50$ & $\sqrt{ }$ & \\
\hline & & 1200 & 0.87 & $0: 21$ & $1: 55$ & $\checkmark$ & \\
\hline & & 1600 & 0.77 & $0: 31$ & 3:44 & $\checkmark$ & \\
\hline & Driving on earthen road $2 W D$ mode & 800 & 0.95 & $0: 18$ & $1: 85$ & $\checkmark$ & \\
\hline & & 1000 & 0.67 & $0: 40$ & $3: 34$ & $\checkmark$ & \\
\hline & & 1200 & 1:01 & $0: 27$ & $2: 23$ & $\checkmark$ & \\
\hline & & 1600 & 0.93 & $0: 22$ & 1:59 & $\checkmark$ & \\
\hline & Driving on earthen road $4 \mathrm{WD}$ mode & 800 & 0.91 & $0: 21$ & $1: 52$ & $\checkmark$ & \\
\hline & & 1000 & 1.15 & $0: 14$ & $1: 17$ & $\checkmark$ & \\
\hline & & 1200 & 1.7 & $0: 5$ & $0: 29$ & $\checkmark$ & $\checkmark$ \\
\hline & & 1600 & 2.87 & $0: 02$ & $0: 10$ & $\checkmark$ & $\checkmark$ \\
\hline \multirow[t]{4}{*}{ Plowing } & $2 \mathrm{WD}$ engaged with mold board & 1200 & 5.55 & $0: 08$ & $0: 43$ & $\checkmark$ & $\checkmark$ \\
\hline & & 1600 & 3.69 & $0: 17$ & $1: 31$ & $\checkmark$ & $\checkmark$ \\
\hline & 4WD engaged with mold board & 1200 & 5.64 & $0: 09$ & $0: 48$ & $\checkmark$ & $\checkmark$ \\
\hline & & 1600 & 3.28 & $0: 15$ & $0: 23$ & $\checkmark$ & $\checkmark$ \\
\hline
\end{tabular}

allowed limits of EAV at $800 \mathrm{rpm}$ and increased as the engine rpm increased to approach the value of Exposure Limit Value ELV at $1600 \mathrm{rpm}$. The figure also shows a rapid increase in vibration as the engine speed changed from $1000-1200 \mathrm{rpm}$, then continue with a gradual and slight increase up to value of $0.96 \mathrm{~min} \mathrm{sec}^{-2}$ at $1600 \mathrm{rpm}$. Regarding the total vibration value $A v$, it was $0.61 \mathrm{~min} \mathrm{sec}^{-2}$ at $800 \mathrm{rpm}$ and shows the same behavior as $\mathrm{Ax}$ axis behave until it reaches its maximum value $1.06 \mathrm{~min} \mathrm{sec}^{-2}$ at $1600 \mathrm{rpm}$ which indicate that the value of Av was effected by Ax values more than other axes Table 2. However; the Av values obtained for the stop site parameter at all engine rpm tested fall within the fairly uncomfortable values defined by ISO (1997).

The above mentioned results indicated that there is unacceptable risk to the tractor driver which requires administrative decisions to reduce working hours. Therefore; the drivers daily Exposure A (8) for EAV and EL V was calculated and the results presented in Table 3. As shown in Table 3 at the stop site parameter, the driver can sit on the tractor driving seat for $3 \mathrm{~h}$ and $58 \mathrm{~min}$ before exceeding the danger limit ELV (1.15 $\left.\mathrm{min} \mathrm{sec}^{-2}\right)$ and only $45 \mathrm{~min}$ to reach the warning limit EAV $\left(0.5 \mathrm{~min} \mathrm{sec}^{-2}\right)$ when the tractor is operating at $800 \mathrm{rpm}$ engine speed. Moreover, the situation becomes more complicated at engine speed $1600 \mathrm{rpm}$ where the driver can only sit $1 \mathrm{~h}$ and $21 \mathrm{~min}$ before exceeding ELV and 15 min only to reach EAV.

Transportation site: The results shown in Table 2 indicate that the whole body vibration WBV emitted by the agricultural tractor during transportation varies according to engine $\mathrm{rpm}$, nature of the roads, type of terrain and dragging kind (2WD or 4WD). Figure 3 a-c show the mobility paths that have been tested for WBV

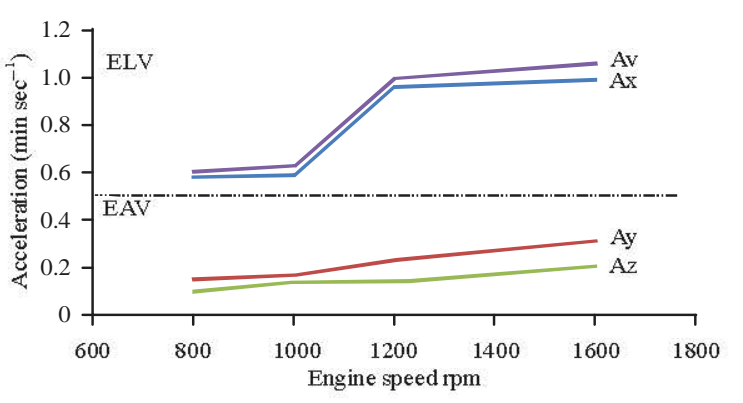

Fig. 2: rms acceleration in $\mathrm{x}, \mathrm{y}, \mathrm{z}$ as effected by different engine speeds during the stop sit test

which was launched by the agriculture tractor during traffic. Regarding the WBV of the Ay and Az axes of the transportation parameters, the charts of Fig. 3a-c showed that their values at the tested engine speeds have no difference as compared with each other. All their values are either below or close to the international warning standard EAV $\left(0.5 \mathrm{~min} \mathrm{sec}^{-2}\right)$. Although, most of Ay and $\mathrm{Az}$ values obtained are located within the not uncomfortable category adopted by ISO (1997) for the overall vibration total values in public transport Table 4 , the results showed that the Ay and $\mathrm{Az}$ values have a significant impact as combined with the most influential axis (in this case $\mathrm{Ax}$ ) when the total vibration outcome effect on the driver body Av is extracted. Concerning the $\mathrm{Ax}$ axis vibration, its values have exceeded the recommended value of the warning limit EAV in case of the asphalt and earthen roads at 2WD mode and below the risk limit ELV value. While in the case of 4WD mode behaved differently, it was below the risk limit ELV value at $800 \mathrm{rpm}$ and equal to the risk limit EL V value at $1000 \mathrm{rpm}$ then began to increase upward to reach a 

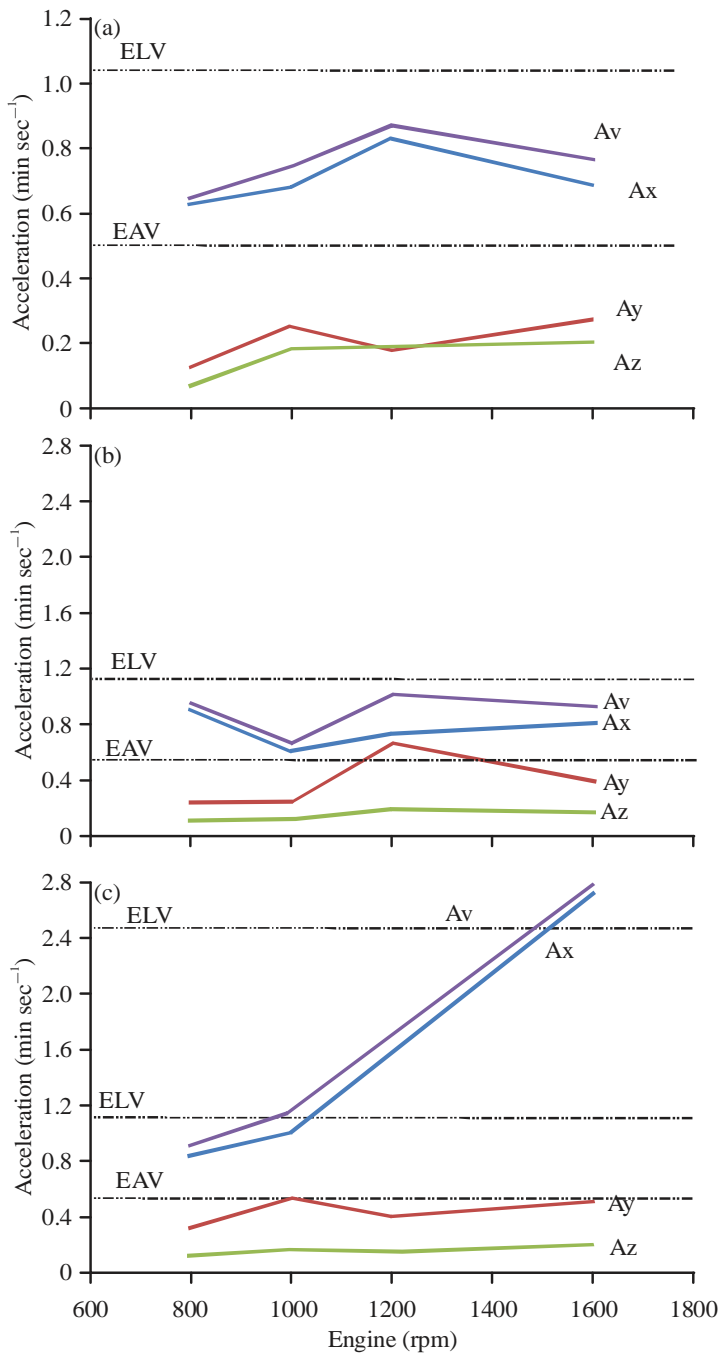

Fig. 3(a-c): rms acceleration in $\mathrm{X}, \mathrm{Y}$ and $\mathrm{Z}$ effected by deferent engine speeds during transportation site (a) Asphalt road, (b) Earthen road $2 \mathrm{WD}$ mod and (c) Earthen road 4 WD mod

high vibration rate of 1.7 and $2.72 \mathrm{~min} \mathrm{sec}^{-2}$ at 1200 and $1600 \mathrm{rpm}$, respectively. These values require implementation of ISO (1997) measures to reduce and manage driver vibration exposure. The relationship between the resultant of total vibration $\mathrm{Av}$ and the vibrating axes with respect to the engine speed and tractor operation is shown in Fig. 3a-c. As the figure shows a clear relationship between $\mathrm{Av}$ and $\mathrm{Ax}, \mathrm{Ay}, \mathrm{Az}$ in all the parameters tested. This is clear from the high correlation between them where requal to $0.97,0.93,0.94$ for $\mathrm{Ax}$, $\mathrm{Ay}$ and $\mathrm{Az}$ respectively. The figure also shows that $\mathrm{Ax}$ is the most closely associated with Av and this is demonstrated by the strong correlation value mentioned earlier.

Although, mobility in the field does not require a long time to accomplish and this means that tractor driving

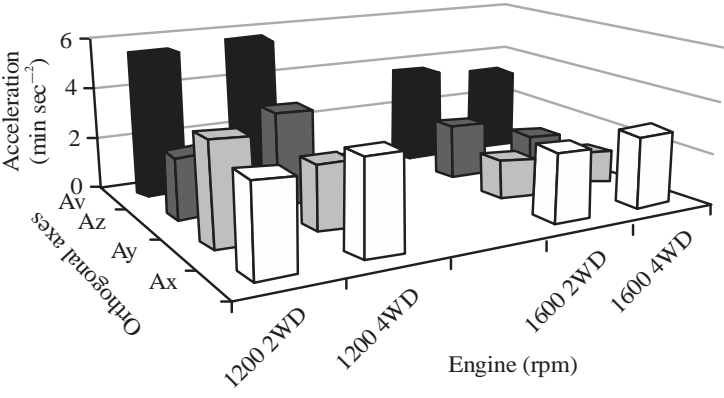

Fig 4: rms acceleration in $\mathrm{x}, \mathrm{y}, \mathrm{z}$ as effected by different engine speeds during the plowing site test

Table 4: Discomfort response to different magnitudes of total vibration values in public transport (ISO 2631-1 1997)

\begin{tabular}{ll}
\hline Magnitude of total vibration & Discomfort response \\
\hline Less than $0.315 \mathrm{~min} \mathrm{sec}^{-2}$ & Not uncomfortable \\
$0.315-0.63 \mathrm{~min} \mathrm{sec}^{-2}$ & A little uncomfortable \\
$0.5-1.0 \mathrm{~min} \mathrm{sec}$ & Fairly uncomfortable \\
$0.8-1.6 \mathrm{~min} \mathrm{sec}$ & Uncomfortable \\
$1.25-1.6 \mathrm{~min} \mathrm{sec}$ & Very uncomfortable \\
Greater than $2.0 \mathrm{~min} \mathrm{sec}$ & Extremely uncomfortable \\
\hline
\end{tabular}

does not pose a risk to the health of the driver, the results in Table 3 indicate unacceptable risks should be disposed of or quickly managed. This fact is evidenced by the short time of the daily exposure A (8) recorded to reach the warning limit EAV and the risk limit ELV which is ranging 2 and $10 \mathrm{~min}$ at $1600 \mathrm{rpm}$ (earthen road 4WD mode) respectively. While, the longest daily exposure $\mathrm{A}(8)$ time recorded to reach the warning limit EAV and the risk limit ELV were $40 \mathrm{~min}$ and $3 \mathrm{~h}$ and $34 \mathrm{~min}$ at $1000 \mathrm{rpm}$ (earthen road 2WD mode) respectively.

Plowing site: The process of plowing did not occur at engine speeds of 800 and $1000 \mathrm{rpm}$ because the power generated at these two speeds is not sufficient to overcome soil resistance, therefore; the results were limited to the engine speeds of 1200 and $1600 \mathrm{rpm}$ during plowing site parameter. Results related to the plowing site shown in Table 2 and 3 indicate that the levels of vibration transmitted to the tractor driver body were very high for all axes and exceeded the level of warning EAV and the level of exposure to the risk ELV. Moreover; most of the vibration levels obtained for both $2 \mathrm{WD}$ and $4 \mathrm{WD}$ at the two speeds tested fall within the category of extremely uncomfortable Table 4 (ISO., 1997). Figure 4 shows that the engine speed of $1200 \mathrm{rpm}$ released more vibration than the $1600 \mathrm{rpm}$ for both 2WD and 4WD at all axes and the reason is that the high speed gives a high power which helps the tractor to reduce the vibration resulting from the obstacles caused by penetration of the soil. Figure 4 also shows that traction method has an effect on vibration but in general seems to be $4 \mathrm{WD}$ was less vibrating than $2 \mathrm{WD}$ and the reason is that $4 \mathrm{WD}$ make the tractor more stable, more compacted to the soil which 
increase its ability to overcome the resistance of the soil and makes it less shaking. Figure 4 shows the magnitude of the total vibration of the tractor seat Av min $\mathrm{sec}^{-2}$. As the figure shows its vibration values has reached levels above the level of danger with values have sometimes exceeded the ELV nearly four times. In contrast to the other treatments where Ax was the most influential in Av, the treatment of plowing has all axes are closely related in terms of the effect, therefore, resulting in a high values of Av. These values were associated with a high positive correlation to all axes. According to the result mentioned in the previous lines, the time duration to reach EAV $(\mathrm{A}(8))$ and $\operatorname{ELV}(\mathrm{A}(8))$ obtained and based on the health hazard assessment of ISO standard, a tractor driver who tended to carry out a plowing work using the tested tractor at the studied parameters, must implement a serious of protection measures.

\section{CONCLUSION}

From the result obtained, it can be concluded that the tractor driver was exposed to unacceptable risk of vibration depending on the type of agricultural operation, road type, terrain and engine speed. The vibration enters the driver body through the orthogonal axes; $\mathrm{X}, \mathrm{Y}$ and $\mathrm{Z}$. At the lowest values of the total vibration, the tractor driver should not be exposed for more than three hours and a half hour, while at the highest values should not be exposed for more than half an hour. So safety hedges and administrative decisions must be taken to determine the time period in which the driver is exposed to vibration during driving a tractor before starting any agricultural process.

\section{REFERENCES}

Barac, Z., I. Plascak, M. Jurisic, I. Vidakovic, M. Markovic and D. Zimmer, 2018. Produced levels of mehanical vibration on cabin of agricultural tractor by different agrotechnical surfaces. Agric. Conspectus Sci., 83: 83-86.

European Communities, 2002. Directive 2002/44/EC of the European parliament and of the council of 25 june 2002 on the minimum health and safety requirements regarding the exposure of workers to the risks arising from physical agents (vibration) (sixteenth individual Directive within the meaning of Article 16(1) of Directive 89/391/EEC). Off. J. Eur. Commun., L177: 13-19.
Fereydooni, M., A.N. Lorestani, H. Rabbani and P. Javadikia, 2012. Measurement and analysis of vibration of operator in Universal 650, Massey Ferguson 285 \& MF 299 tractors. Int. J. Mech. Applic., 2: 88-92.

ISO., 1997. ISO 2631-1:1997: Mechanical vibration and shock-evaluation of human exposure to whole-body vibration-Part 1: General requirements. Organization for Standardization (ISO), Geneva, Switzerland. https://www.iso.org/standard/7612.html

ISO., 2004. ISO 2631-5: 2004 Mechanical vibration and shock evaluation-part5: Method for evaluation of vibration containing multiple shocks. International Organisation for Standardization, Geneva, Switzerland. https://www.iso.org/standard/ 35595.html

Karthik, A., N.B. Shaik, G.S. Praveen and A.R.S. Reddy, 2017. Vibration analysis on Tractor bonnet. Int. J. Innovative Res. Sci. Technol., 4: 45-48.

Kitazaki, S. and M.J. Griffin, 1997. Resonance behaviour of the seated human body and effects of posture. J. Biomech., 31: 143-149.

Mehta, C.R., M. Shyam, P. Singh and R.N. Verma, 2000. Ride vibration on tractor-implement system. Applied Ergon., 31: 323-328.

Monaghan, S.J. and D.C. van Twest, 2004. Whole-body vibration-review of Australian and international standards and the future. Proceedings of the Annual Conference of the Australian Acoustical Society on Transportation Noise and Vibration-The New Millennium, November 3-5, 2004, Australian Acoustical Society, Gold Coast, Australia, pp: 609-614.

NFU Mutual Risk Management Services Limited, 2017. Health and safety guidance note-risk assessment. Version 1.2, 2017. NFU Mutual Risk Management Services Limited (No. 350057), England.

Scarlett, A.J., J.S. Price and R.M. Stayner, 2007. Whole-body vibration: Evaluation of emission and exposure levels arising from Agricultural tractors. J. Terramech., 44: 65-73.

Scarlett, A.J., J.S. Price, D.A. Semple and R.M. Stayner, 2005. Whole-Body Vibration on Agricultural Vehicles: Evaluation of Emission and Estimated Exposure Levels. Vol. 321, HSE Books, New York, USA., Pages: 231. 